\title{
Synthesis of New Curcuminoid Derivatives with Potential Antioxidant and Hypoglycemic Properties
}

\begin{tabular}{|c|}
\hline 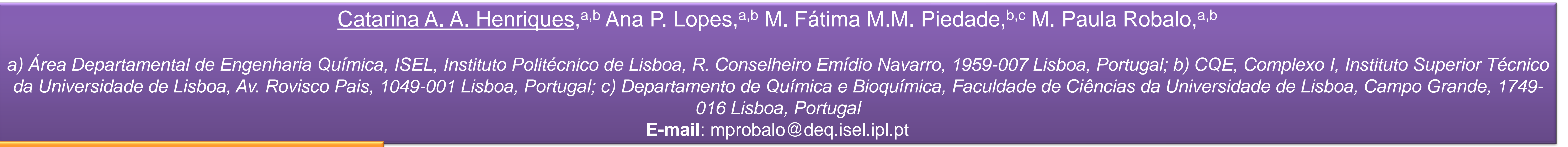 \\
\hline Introduction \\
\hline $\begin{array}{l}\text { Curcumin is the principal constituent of turmeric i.e., the ground rhizomes of Curcuma longa. This compound has been used to therapeutic or protective effects } \\
\text { against a variety of diseases such as cancer, lung, neurological, liver, metabolic, autoimmune, cardiovascular and numerous other chronic diseases. For this } \\
\text { reason, curcumin is considered a nutraceutical that present some disadvantages such as its insolubility and stability in water. }{ }^{1} \text { Recent studies with diabetic rats } \\
\text { suggest that substitution of the central position on the } \beta \text {-diketone chain leads to curcuminoid derivatives that potentiate the effects of curcumin, improving the } \\
\text { fasting glucose and the endothelial function on type } 2 \text { diabetes. }{ }^{2} \text { Therefore, this work presents the synthesis of curcuminoid derivatives (scheme } 1 \text { ) }{ }^{3,4} \text { where } \\
\text { several modifications have been introduced to the curcumin structure, such as the introduction of different groups in the } \beta \text {-diketone chain, the exchange of }\end{array}$ \\
\hline
\end{tabular}

\section{Synthesis}

Functionalization of a-position

$$
2 \mathrm{R}_{1}=\mathrm{OCH}_{3} ; \mathrm{R}_{2}=\mathrm{OH} \quad \mathrm{\eta}=48 \%
$$

\section{Curcuminoids Synthesis}

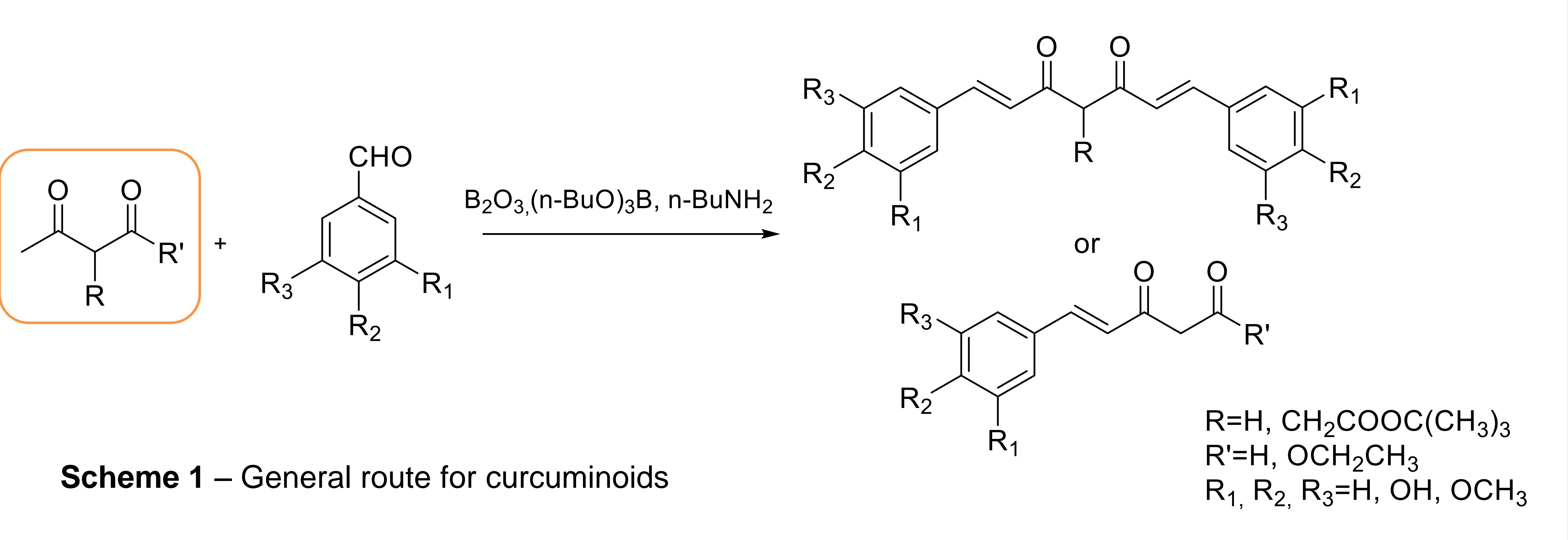

\section{Results}

\section{Compounds}<smiles>[R]C1=C([R])CC(/C=C/C(=O)C(CC(=O)OC(C)(C)C)C(=O)/C=C/c2ccc([R])c([R2])c2)C=C1</smiles>

$6 \mathrm{R}_{1}=\mathrm{OH} ; \mathrm{R}_{2}=\mathrm{OCH}_{3} ; \eta=58 \%$

$7 \mathrm{R}_{1}=\mathrm{OCH}_{3} ; \mathrm{R}_{2}=\mathrm{OH} ; \mathrm{\eta}=75 \%$<smiles>[R]C1=C([R])C([R])=C(/C=C/C(=O)CC(=O)/C=C/c2cc([R2])c([R])c([R])c2)C1</smiles>

$8 \mathrm{R}_{1}=\mathrm{OH} ; \mathrm{R}_{2}=\mathrm{OCH}_{3} ; \mathrm{R}_{3}=\mathrm{H} ; \quad \eta=72 \%$ $9 \mathrm{R}_{1}=\mathrm{OH} ; \mathrm{R}_{2}, \mathrm{R}_{3}=\mathrm{H} ; \quad \eta=81 \%$ $10 \mathrm{R}_{1}=\mathrm{OH} ; \mathrm{R}_{2}, \mathrm{R}_{3}=\mathrm{OCH}_{3} ; \quad \eta=80 \%$<smiles>[R]c1cc(/C=C/C(=O)CC(=O)OCC)cc([R])c1[R]</smiles>

$\mathrm{R}_{1}=\mathrm{OCH}_{3} ; \mathrm{R}_{2}=\mathrm{OH} ; \mathrm{R}_{3}=\mathrm{H} \quad \eta=84 \%$

$12 \mathrm{R}_{1}=\mathrm{OH} ; \mathrm{R}_{2}=\mathrm{OCH}_{3} ; \mathrm{R}_{3}=\mathrm{OCH}_{3}$<smiles>[R]c1cc(/C=C/C(=O)CC(C)=O)cc([R])c1[R]</smiles>

$3 \mathrm{R}_{1}=\mathrm{OCH}_{3} ; \mathrm{R}_{2}=\mathrm{OH} ; \mathrm{R}_{3}=\mathrm{H} \quad \eta=64 \%$

$14 \mathrm{R}_{1}=\mathrm{OH} ; \mathrm{R}_{2}=\mathrm{H} ; \mathrm{R}_{3}=\mathrm{H} \quad \eta=78 \%$

$\mathrm{R}_{1}=\mathrm{OH} ; \mathrm{R}_{2}=\mathrm{OCH}_{3} ; \mathrm{R}_{3}=\mathrm{OCH}_{3} \quad \eta=52 \%$

\begin{tabular}{|c|c|c|}
\hline Compound & DK form (\%) & KE form (\%) \\
\hline (6) & 34 & 66 \\
\hline (7) & 27 & 83 \\
\hline (8-10) & 0 & 100 \\
\hline (11) & 0 & 100 \\
\hline (13) & 0 & 100 \\
\hline
\end{tabular}

\section{Keto-enol tautomerism}

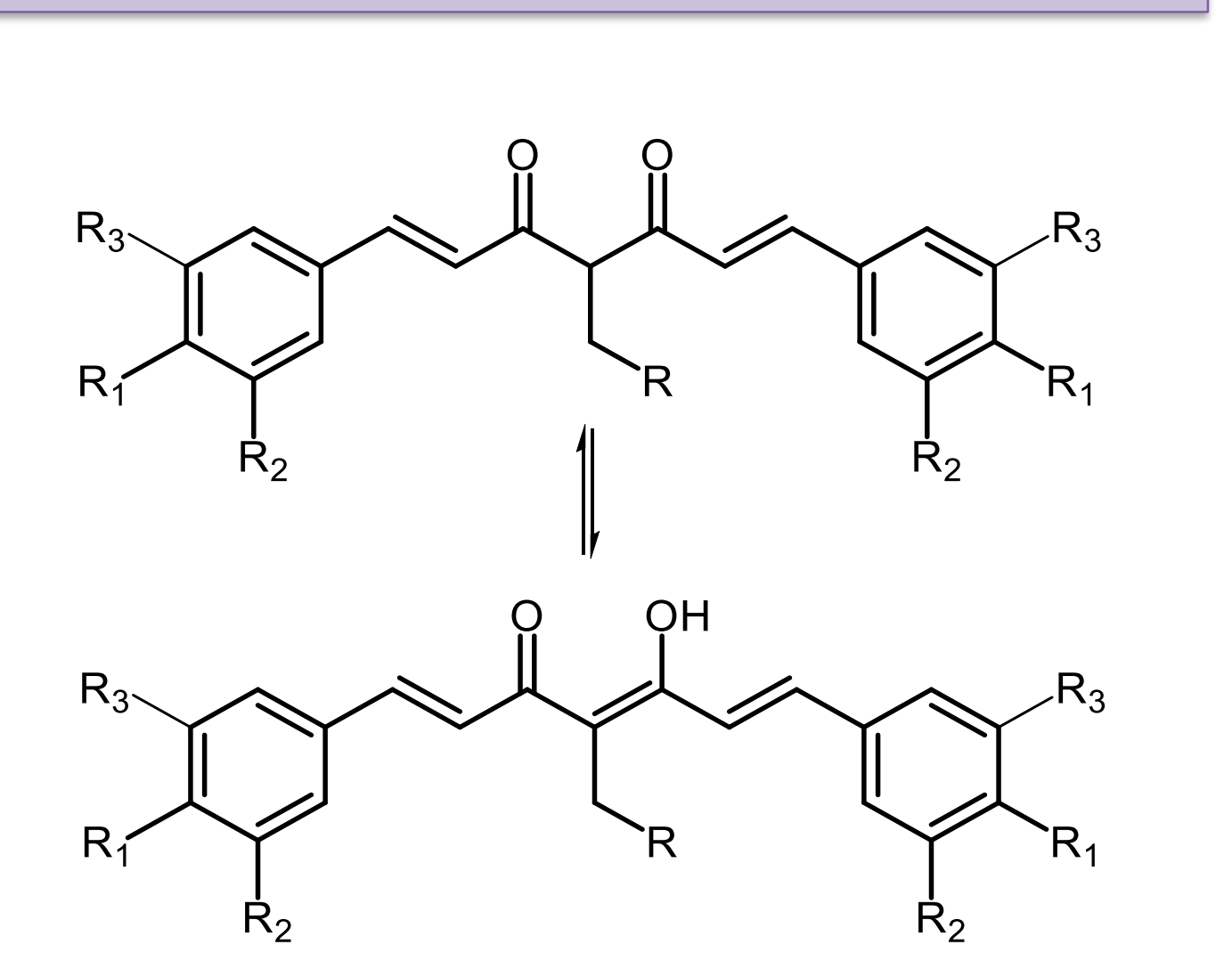

Antioxidant Capacity

ABTS Test (at $734 \mathrm{~nm}$ )

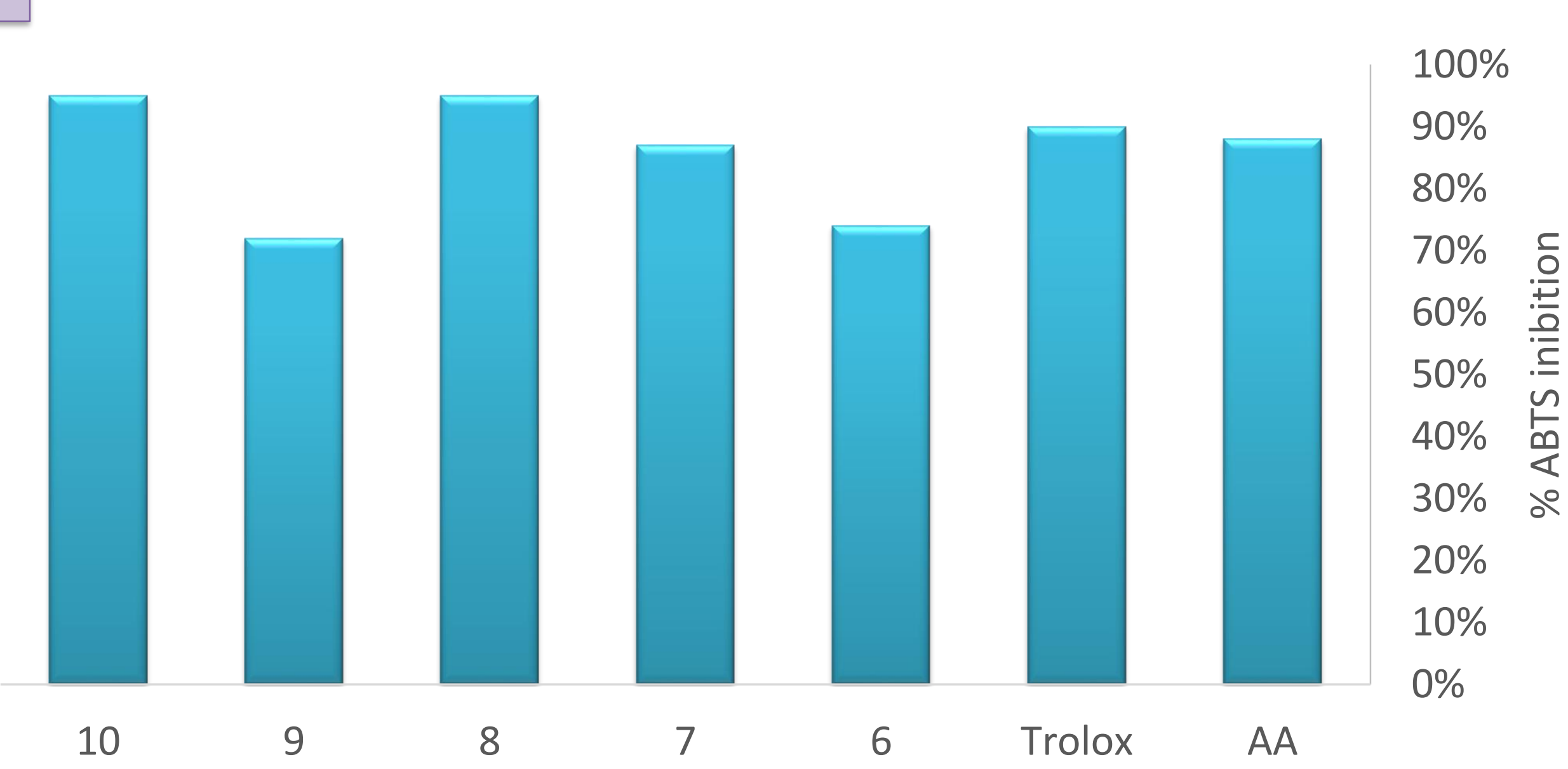

\section{Conclusions}

- The general synthetic routes proposed seemed to be convenient for the formation of the curcumin analogous with high purity and good to excellent yields.

- The $\alpha$-substituent plays a crucial role in establishing the keto-enol tautomerism characteristic of these $\beta$ diketones. NMR analysis allowed the evaluation of keto-enolic tautomerism in solution for these compounds: except for compounds 6 and 7, which have both forms, all other compounds are in the enolic form; the X-ray structures of compounds 6 and 10 show the two different forms in the solid state.

- Curcumin showed higher antioxidant capacity than ascorbic acid (AA) and trolox; the presence of methoxy groups adjacent to the $\mathrm{OH}$ group seems to be important for the antioxidant capacity (compound 10). However, the exchange of positions of this group with $\mathrm{OH}$ (compounds 6 and 7 ) lowers the antioxidant capacity.

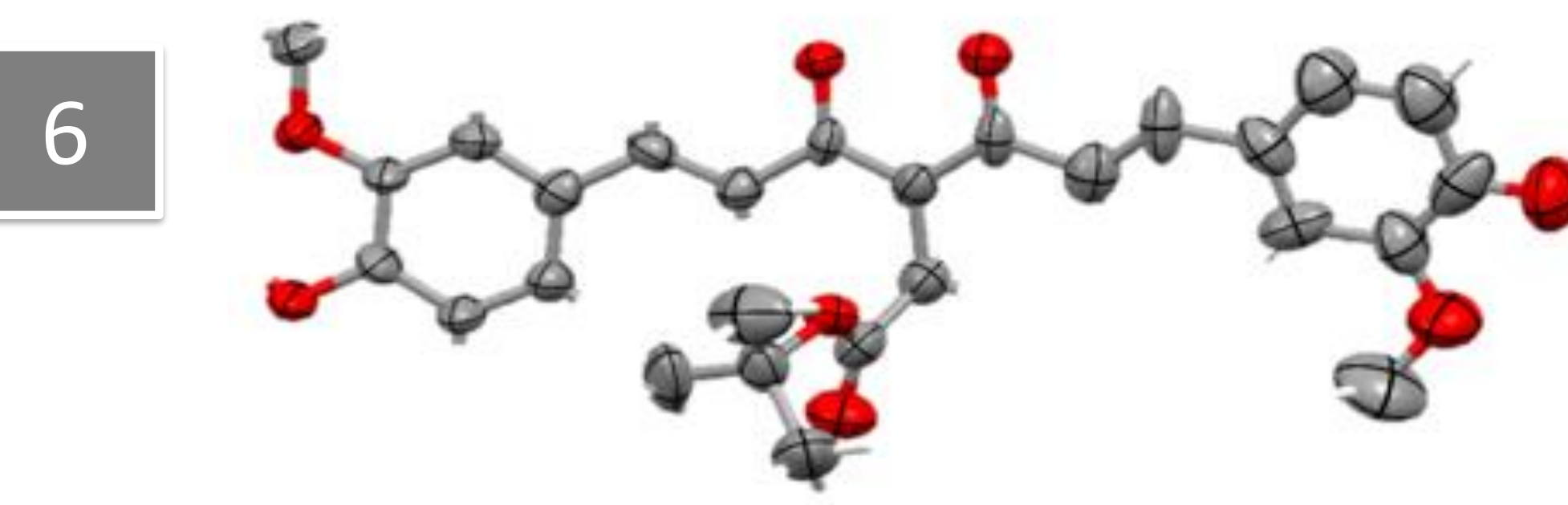

Space group: Monoclinic, P21/n

10

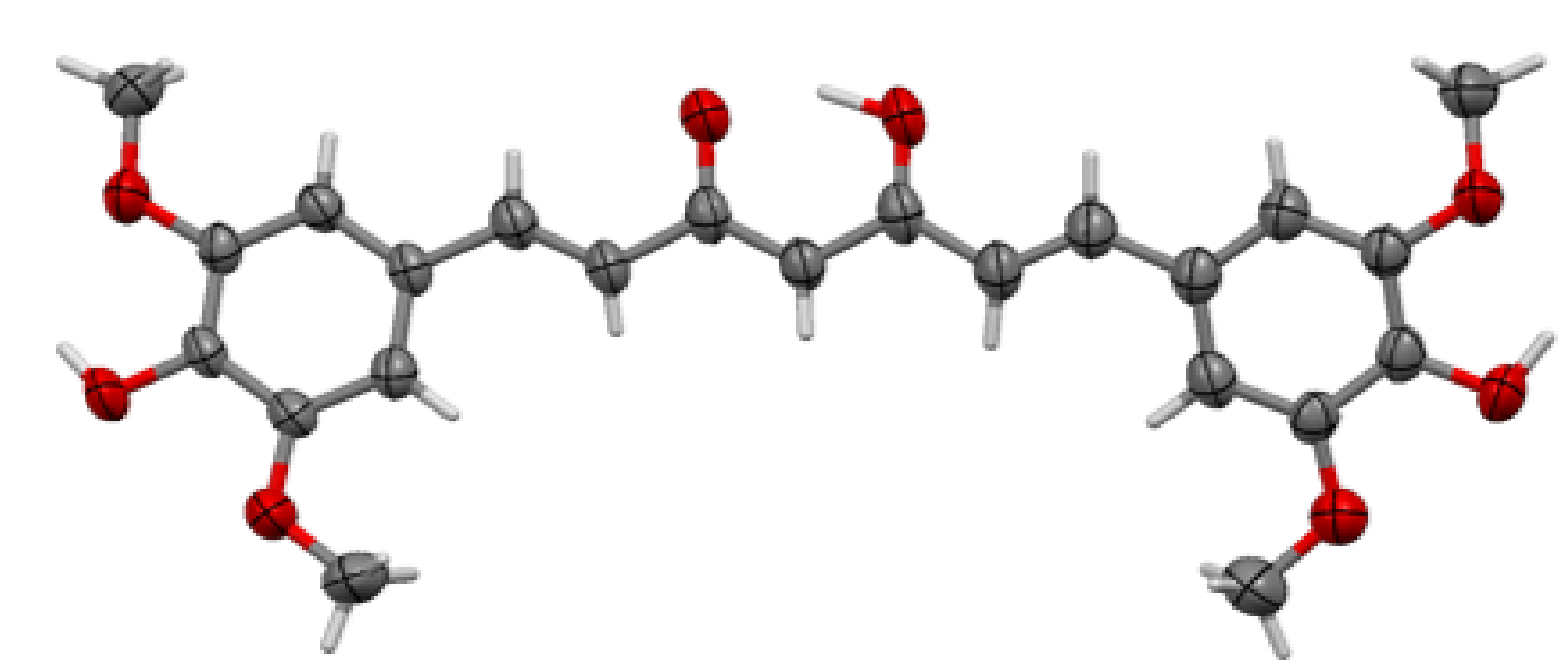

Space group: Monoclinic, $\mathrm{P} 121 / \mathrm{c} 1$

Solubility Tests

Solubility in water: $2.5 \times 10^{-5}$ to $1.0 \times 10^{-4} \mathrm{M}$

\section{References}

1. Gupta SC, Patchva S, Koh W, et al. Discovery of Curcumin, a Component of the Golden Spice, and Its Miraculous Biologica Activities. Clin Exp Pharmacol Physiol. 2012;39(3):283-299.

Oliveira S, Monteiro T, Henriques L, et al. Development of a curcumin derivative with hypoglycemic properties: Impact on oxidative stress and endothelial function in type 2 diabetes. Eur J Clin Invest. 2019;49:125.

Martichonok V V, Chiang PK, Dornbush PJ, et al. On Regioselectivity of Aldol Condensation of Aromatic Aldehydes with Borate Complex of
Acetylacetone. Synth Commun. 2014;44(9):1245-1250. doi:10.1080/00397911.2013.850094

Stanchev S, Jensen F, Manolov I. Synthesis and DFT Study of the Sprectral Behavior of New 4-Hydroxycoumarins. Int $J$ Quantum Chem. 2008;108(8):1340-1351 